\title{
KEARIFAN LOKAL DALAM NOVEL GENDUK KARYA SUNDARI MARDJUKI (KAJIAN SOSIOLOGI SASTRA)
}

\author{
Anisa Disma Cahyana Sukri Pertiwi \\ Program Studi Pendidikan Bahasa Indonesia Fakultas Keguruan dan Ilmu Pendidikan, \\ Universitas PGRI Adi Buana Surabaya \\ aniisaadis10@gmail.com \\ Eko Cahyo Prawoto \\ Program Studi Pendidikan Bahasa Indonesia \\ Fakultas Keguruan dan Ilmu Pendidikan, Universitas PGRI Adi Buana Surabaya \\ ecahyop@gmail.com
}

\begin{abstract}
In this ressearch, the aim of this ressearch is (1) describe the aspects of welfare, (2) to describe the aspects of peace. The method used is descriptive qualitative and sociology of literature and uses the object of aspects of welfare and aspects of peace in the novel Genduk by Sundari Mardjuki. Data collection techniques, namely reading over and over, marking data, and recapitulating data. Data analysis techniques use categorizing and creating tables. The validity of the data used the validity test, data reliability and stability test. This study uses the theory of Robert Siabrani. Local wisdom has two aspects, namely, the welfare aspect and aspects of peace. The daata source used is the novel Genduk by Sundari Mardjuki. The research data is the form of quootations. The results of research on Sundari Mardjuki's novel Genduk show that the environment in the story is set in the 1970s. The Genduk and Yung characters live in Ringinsari Village, near Mount Sindoro. In the story of the character Yung, the way to ask God is very different, the character Yung always uses chanting from ancient times. The village still preserves its culture, such as Among Thickness, Kenduri, Jatilan, and cutting hair from the spikes.
\end{abstract}

Keywords : local wisdom, aspects of welfare, and aspects of peace.

\section{PENDAHULUAN}

Dalam karya sastra memiliki tiga genre, yaitu drama, puisi, dan fiksi. Karya sastra bagian genre fiksi ialah novel. Novel mengisahkan perjalanan kehidupan manusia yang melibatkan tokoh utama dalam karya sastra. Novel menjadi bagian karya sastra yang mengemas tentang kehidupan yang ideal, imajinatif, dan dibangun dari unsur intrinsik meliputi gaya bahasa, amanat, sudut pandang, penokohan, tokoh, latar, alur dan tema (Nurgiyantoro, 2007).
Novel Genduk karya Sundari Mardjuki menggambarkan tahun 1970-an tentang proses pertanian tembakau dari penanam sampai panen tembakau. Pengarang menggunakan tokoh utamanya perempuan yang panggilannya Genduk berusia belasan tahun yang hidup dekat dengan Gunung Sindoro bertahan hidup bersama ibunya. Kehidupan masyarakat Gunung Sindoro mata pencariannya semua petani tembakau. Pada saat awal musim penanaman tembakau melakukan sebuah tradisi turun dari leluhurnya, yaitu tradisi Among Tebal. Tradisi 
Among Tebal memiliki tujuan untuk meminta terhadap Tuhan supaya panen tembakau menjadi berlimpah serta serangan hama tidak menyerang tembakau. Awal penanaman bibit tembakau melakukan secara hati-hati saat penyiraman dan selalu melakukan pengecekan berkala bertujuan untuk mengawasi atau melihat pertumbuhan bibit tembakau dengan baik atau tidak.

Apabila pada saat pengecekan tembakau ada yan mati, langsung digantikan menggunakan bibit baru. Bibit tembakauu sudah meniinggi akan memunculkan tunas pada sela daun, petani langsung melakukan pemotongan tunas atau disebut ngrewos bertujuan agar tunas tersebut tidak tumbuh. Selain itu, pemotongan tunas membuat sari makanan dapat sampai secara langsung pada daun. Jika, tanaman tembakau sudah berbunga, petani akan melakukan pemotongan atau pemangkasan pada bunga yang disebut punggel.

Tujuan melakukan pemangkasan pada bunga supaya tidak berkembang, membuat daun tembakau menjadi subur dan lebat. Daun tembakau yang telah siap untuk dipetik harus dibedakan Penelitian ini bertujuan untuk memgetahui dan mendeskripslkan aspek kesejahteraan dan aspek kedamaian pada kearifan lokal pada novel Genduk karya Sundari Mardjuki.

\section{METODE}

Pada penelitian ini menggumakan dua metode pendekatan, yaitu pendekatan sosiologi sastra dan pendekatan kualitatif deskriptif. Menurut Kaelan (2005:

58) pendekatan deskriptif merupakan pendekatan yang digunakan untuk kualitasnya. Daun tembakau yang sudah lemas akan dilakukan perajangan. Setelah, melakukan perajangan lalu dijemur sampai kering. Kemudian, daun-daun tembakau yang sudah kering dapat dijual.

Pemilihan novel Genduk untuk penelitian ini, karena kearifan lokal dari kisah masyarakat sangat kental. Oleh karena itu, novel ini sangat menarik karena budaya lokal dalam kehidupan masyarakat sangat diperhatikan. Hal tersebut, dapat menjaga kelestarian kebudayaan untuk generasi selanjutnya. Kearifan lokal dalam bentuk tradisi lisan sangat berkembang pada pedesaan.

Tujuan untuk berkembangnya kearifan lokal sebagai penghayatan nilai-nilai unsur adat istiadat, moral, sosial, bahasa dan status pekerjaan dalam anggota masyarakat. Berkat, pengetahuan lokal atau setempat merupakan solusi kehidupan untuk memecahakan berbagai masalah yang dihadapi secara langsung. Pengetahuan lokal atau setempat kadang dianggap tidak relevan untuk kebutuhan produktivitas pada dunia modern.

meneliti sebuah objek yang bermuatan nilai kebudayaan manusia, filsafat, sistem dalam pemikiran, nilai-nilai etika sekelompok manusia dan nilai-nilai karya seni. Sosiologi sastra merupakan suatu tanpa bentuk kedisplinan, tak mendefinisikan dengan benar, terdiri atas pelajaran empiris dan beberapa pengujian yan bersifat general yang memiliki persamaan tentag hubungan sastra dengan masyarakat (Wolf (dalam Endraswara, 2008: 77).

Data penelitian ini, yaitu kalimat tuturan tokoh dan kutipan 
pada novel yang terkandung kearifan lokal. Sumber data berupa novel Genduk karya Sundari Mardjuki. Novel yang dicetak oleh PT. Gramedia Pustaka Utama di Jakarta pada tahun 2016 yang jumlah halamanya 232 halaman dan panjangnya $20 \mathrm{~cm}$. Novel yang bersampul warna biru muda dan bagian depannya bergambar dua helai daun tembakau berwarna jingga serta ada tulisan judul novel berbentuk perekat berwarna krem yang menindihi daun tembakau.

Teknik pengunpulan data padaa penelitian ini meliputi membaca denggan tuntas dan berulang-ulang agar benar-benar memahami urutan peristiwa yang diungkapkan oleh pengarang novel Genduk karya Sundari Mardjuki, menandai data yan menunjukan keaarifan lokal masyarakat dengan menggarisi bawahi kalimat dalam tuturan tokoh pada novel Genduk karya Sundari Mardjuki, dan merekap data berupa kalimat dari tuturan tokoh yang menunjukan kearifan lokal. Teknik analisis data yang digunakan dalam penelitian, yaitu kategorisasi serta penyajian data. Keabsahan data dapat dipertanggungjawabkan melalui uji validitas, reliabilitas data, dan uji stabilitas.

\section{HASIL PENELITIAN DAN PEMBAHASAN}

Pada penelitian ini menghasilkan pembahasaan mengenai dua aspek, yaitu aspek kesejahteraan dan kedamaian pada novel Genduk karya Sundari Mardjuki. Aspek kesejateraan meliputi (1) pendidikan, (2) kerja keras, (3) gotong royong, (4) pengelolaan gender, (5) pelestarian budaya, (6) peduli lingkungan. Aspek kedamaian meliputi kesetikawanan sosial, penyelesaian konflik,

kesopansantunan, (4) rasa syukur, (5) pikiran positif, (6) kejujuran.

1. Aspek Kesejateraan pada Novel Genduk Karya Sundari Mardjuki

Aspek kesejahteraan ada tujuh sebagai berikut :

a. Kerja Keras

Menurut Sibarani (2014:146)

kerja keras ialah perbuatan yang memperlihatkan suatu usaha yang sungguh-sungguh dalam menangani berbagai rintangan dam menyelesaikan tugas dengan sebaikbaiknya. Kutipan yang menunjukkan kerja keras, yaitu :

Semua pekerjaanku sudah kuselesaikan dengan baik. Airdalam gentong sudah kuisi penuh. Perlu waktu hingga tiga kali bolak-balik untuk membawa kendi demi mengisi air dari mata air Tuksari di ujung desa ke rumah. Lantai rumah sudah kusapu bersih dan kuciprati air dengan merata sehingga tidak ada debu yang menghambur. Makan malam sudah kusiapkan. Sego jagung, sambal aking, dan gereh petek.

(Mardjuki, 2016: 20-21).

Dalam kutipan di atas menunjukan kerja keras, karena tokoh Genduk telah menyelesaikan tugas dengan sungguh-sungguh. Genduk telah mengisi air gentong sampai penuh yang di ambil dari air Tuksari dengan menggunakan kendi. Selain itu, Genduk juga menyapu, menyiprati air agar lantai tidak berdebu, dan menyiapkan makan malam.

b. Pendidikan Menurut, Wulan Dary (2017) pendidikan merupakan proses 
pengembangan kemampuan diri dapat diperoleh dari luar. Pendidikan juga disebut suatu usaha yang mengembangkan dan membina kepribadian yang dimiliki manusia baik rohani maupun jasmani. Kutipan yang sesuai dengan pendidikan berbunyi :

"Bapakmu itu lagi gandemgandemnya. Muda, bersemangat mempelajari agama. Pokoke yang tidak sesuai syariat, sikat!" Kaji Bawon masih terkekeh." (Mardjuki, 2016: 31) Pada kutipan di atas menunjukan karakter pendidikan, karena tokoh bapak Genduk semasa muda dengan semangat-semangatnya belajar tentang agama yang dikatakan oleh Kaji Bawon. Hal ini, menjelaskan bahwa tokoh bapak telah mengembangkan potensi diri untuk dapat membina kepribadian yang baik.

\section{c. Gotong Royong}

Gotong royong merupakan suatu keglatan yang dilakukam manusia yang saling tolpngmenolong, saling membantu yang membawakan suatu manfaat untuk sekitarnya. Hal ini, ditunjukan pada kutipan di bawah ini : Pak'e ikut dalam acara selamatan desa. Memimpin doa bersama dengan membaca Al Fatihah. Mengajari anak-anak kecil mengaji. Di atas tanah desa kemudian dibangun langgar, bangunan sederhana dengan dinding sebagian seng dan sebagian papan kayu. Pak'e yang mengajak penduduk bergotong royong membangunnya. (Mardjuki, 2016: 27)

Kutipan di atas menunjukan gotong royong, karena tokoh Pak'e mengajak penduduk untuk membangun langgar sederhana dari dinding seng dan kayu. Perilaku yang dilakukan penduduk tersebut, kegiatan yang dilakukan secara bersama-sama.

\section{d. Pengelolaan Gender}

Menurut Handayani dan Sugiarti (2008: 2) telah meluruskan bahwa kata gender berarti ketidakadilan sosial terhadap hubungan antara jenis kelamin. Pengelolaan gender dapat membantu memahami kaum perempuan untuk membedakan antara sex serta gemder. Kata gender dalam bahasa Indonesia tidak ditemukan. Kata gender pada bahasa Inggris menjadi dua kata seks serta gender, kedua kata tersebut berarti jenis kelamin. Dalam membedakan antara kaum perempuan dengan ketidakadilan sosial. Sebelumnya, definisi tentang seks merupakan pembagian jenis kelamin yang sudah ditentukan secara biologis yang sesuai jenis kelamin yang ditentukan. Kutipan yang menunjukan pengelolaan gender di bawah ini :

Sehari-harinya, Yung banyak berladang di lahan sewaan. Pak'e tidak banyak membantu. Setiap kali pulang macul, tangan Yung memerah dan melepuh. Pak'e juga tidak cakap untuk merajang daun tembakau.

(Mardjuki, 2016: 28) Pada kutipan di atas telah menunjukkan pengelolaan gender, karena Yung seorang wanita sejak masih muda sampai mempunyai suami masih berladang dari mencabuti rumput dan mencangkul. Hal ini, menunjukan bahwa tokoh Yung menjadi seorang 
wanita yang melakukan pekerjaan seperti laki-laki.

e. Pelestarian Budaya Menurut Fadli Rahman Wahidi (2017) pelestarian merupakan pemanfaatan suatu sunber daya terhadap tempat demgan adaptasi dan menggunakan fungsi baru serta tidak menghillangkan makna kehidupan budaya. Secara umum, pelestarian, yaitu kegiatan yang melindungi objek pelestarian yang mempunyai nilaai guna yang tinggi. Budaya berasal dari bahasa Sansekreta budhi, dalam bentuk jamak buddhayah yang berarti pikiran dan akal. Budaya dalamnya terdapat pegetahuan, keseniaan, kepercayaan, moral, adat istiadat, hukum yang berasal dari kemampuan masyarakat. Kutipan yang menunjukkan pelestarian budaya dalam novel Genduk berbunyi :

Semesta sepertinya paham bahwa hari ini adalah hari istimewa bagi petani lereng Sindoro. Matahari bersinar hangat, menguapkan kabut tipis, mengeringkan titik-titik embun yang menempel di rumput. Senyum tersungging di wajah setiap orang. Semua berarak menuju mata air Tuksari. Ini adalah hari wiwitan, awal musim menanam tembakau. Sudah menjadi tradisi bagi penduduk seputar lereng Sindoro untuk melakukan ritual Among Tebal, tradisi memohon pada Gusti Allah agar panen melimpah.

(Mardjuki, 2016: 46-47) Kutipan di atas termasuk dalam pelestarian budaya, karena para penduduk lereng Sindoro mengadakan acara wiwitan ritual Among Tebal, yaitu tradisi untuk meminta kepada Tuhan supaya panen tembakau menjadi berlimpah.
Acara ini dilakukan di air Tuksari secara berarakan, setiap

awal musim

penanaman

tembakau.

\section{f. Peduli Lingkungan}

$$
\text { Peduli lingkungan }
$$

merupakan suatu perilaku yang mengatasi kerusakan lingkungan baik alam dan sekitarnya serta meningkatkan upaya perbaikan kerusakan alam yang telah terjadi (Sibarani, 2014: 148). Kutipan dalam novel Genduk yang menunjukan peduli lingkungan, yaitu :

Tanaman ini sudah menguji nyali petani sejak awal ketika ladang dipaculi, ditanami, sampai dipanen. Pupuk menjadi momok karena berarti harus ada uang ditangan untuk membelinya. Nanjaki menjadi momok kedua. Benih yang sudah ditanam harus dijaga betulbetul agar tidak mati karena kalah dengan gulma. Kalau terpaksa mati, harus cepat-cepat diganti dengan bibit yang baru.

(Mardjuki, 2016: 23) Berdasarkan kutipan di atas termasuk peduli lingkungan, karena para petani tembakau harus dapat menjaga tembakau dari awal penanaman sampai panen tembakau. Apabila, bibit tembakau termakan gulma harus cepat diganti dengan bibit baru.

2. Aspek Kedamaian pada Novel Genduk Karya Sundari Mardjuki Aspek kedamaian ada tujuh sebagai berikut :

a. Kesopansantunan

Kesopansantunan merupakan suatu perilaku yang dimiliki seseorang 
dapat memberikan pandangan secara baik dan sopan (Staff, 2018). Kutipan yang menunjukan kesopansantunan ialah

Aku beringsut untuk berpindah. Tapi ruang gerakku sempit. Aku harus segera angkat kaki. Satu menit saja aku bertahan, kencingku pasti mengucur. Dan aku ambil langkah.

"Nuwun sewu, Pakde... Nuwun sewu, Lik..." Aku permisi pada orang-orang yang kulangkahi.

(Mardjuki, 2016: 40) Pada kutipan di atas menunjukan kesopansantunan, karena Genduk beringinan ingin keluar, namun banyak orang lalu Genduk mengucapkan nuwun sewu yang berati permisi. Jika dihubungkan dengan teori tokoh Genduk berperilaku positif, karena telah mengucapan nuwun sewu

saat beringinan untuk keluar dari ruangan.

\section{b. Kejujuran}

$$
\text { Kejujuran merupakan }
$$

perilaku yang dapat dipercayai serta memberikan pengaruh positif untuk seseorang. Kejujuran merupakan suatu perilaku yang terpuji yang dilakukan seseorang dengan menggunakan jujur dan tidak curang (Siti Fadillah, 2016). Kutipan yang ditunjukkan dalam novel Genduk berbunyi :

"Genduk telah membuka jalan kita untuk bisa menjual langsung pada pembeli tembakau yang tepat. Semoga sampeyan-sampeyan tidak lagi tertipu oleh ulah para gaok. Yang penting tembakau diolah dengan jujur, ndak perlu pakai tambahan macam-macam, kita harus percaya diri dengan hasil panenan kita. Setuju?!" tanya Pak Lurah Cokro.

(Mardjuki, 2016: 177-178) Berdasarkan kutipan di atas termasuk kejujuran, karena Pak Lurah Cokro mengimbau untuk bertindak jujur dalam mengelola daun-daun tembakau. Sesuai dengan teori tersebut, bahwa Pak Lurah Cokro memberikan saran agar para petani mengolah daun-daun

temabakau dengan jujur tanpa ada campuran apapun.

\section{c. Kesetikawanan Sosial}

Kesetikawanan sosial dapat disebut solidaritas sosial adalah suatu potensi yang spiritual dan komitmen dalam jati diri yang dimiliki bangsa. Maka, kesetikawanan sosial berasal dari nurani kebangsaan Indonesia baik sikap dan tingkah laku yang berdasarkan tanggun jawab, kesadaran, dan partisipasi sosial dalam kemampuan diri dalam masyarakat melalui senangat kebersamaan, kerelaan untuk bekorban demi sesama dalam keberrsamaan serta kekeluargaan (Sarah, 2014). Kutipan yang ditunjukkan dalam novel Genduk berbunyi :

Ketika aku berjalan beberapa langkah, tiba- tiba ada bocah dengan sepeda roda tiga yang meluncur dari bangunan itu ke arah jalanan besar. Sepeda itu meluncur dengan cepat karena jalanannya menurun. Terdengar suara teriakan di belakang sepeda itu. Sementara di sisi kiriku ada truk yang sedang berjalan mundur. Secepat kilat kuraih sepeda itu. Aku sempat terseret beberapa langkah tapi tanganku tetap 
mencengkeram kuat setang sepeda. Sepeda itu terhenti pada jarak satu lengan dari truk yang sedang bergerak mundur. Terdengar orang berteriakteriak sambil menggedor truk untuk berhenti.

Jantungku seperti mau loncat. Tanganku yang berkeringat masih mencengkeram setang sepeda. Sementara bocah yang ada di sepeda itu tampak santai saja. Seolah tidak terjadi apa-apa. Bocah laki-laki yang kutaksir seumuran dengan Darmaji itu justru tertawa nyengir, memperlihatkan dua giginya yang ompong.

Kedua kakiku terasa lemas dan nyaris tidak menyetuh tanah. Sedetik saja terlewat, bocah ini bisa terlindas truk. Aku tidak bisa membayangkan jika bocah itu tergilas roda truk yang besar- besar.

(Mardjuki, 2016: 120) Pada kutipan di atas menunjukkan kesetiakawanan sosial, karena Genduk menyelamatkan anak kecil dari truk yang sedang berjalan. Sesuai dengan teori tersebut, bahwa Genduk rela berkorban demi menolong anak kecil yang sedang bersepedaan dari truk yang berjalan mundur.

\section{d. Penyelesaian Konflik}

Penyelesaian konflik merupakan penyelesain masalah yang dilakukan suatu kelompok atau dua orang yang memiliki tujuan untuk menghancurkan pihak lain agar tidak berdaya (Faisal,2013). Kutipan yang ditunjukkan dalam novel Genduk berbunyi :

Yung dan Lik Ngadun terkejut ketika aku tiba-tiba ada di hadapan mereka. Mereka pasti mengira aku sudah tidur. "Yung, Lik, aku sudah menguping pembicaraan kalian. Aku tahu masalah apa yang sedang kalian hadapi," kataku dengan suara berapiapi. "Kamu ngerti apa?" sela Yung memotong pembicaraanku.

Lik Ngadun menepiskan lengannya ke tangan Yung, memberikan kode pada Yung untuk diam. "Teruskan, Nduk!" kata Lik Ngadun. "Bah Djan. Tjo Tian Djan kan maksud kalian? Aku akan temui dia!" kataku mantap.

(Mardjuki, 2016: 163) Berdasarkan kutipan di atas menunjukkan penyelesaian konflik, karena Genduk akan menyelesaikan permasalahan mengenai permasalahan tentang tembakau. Langsung Genduk berbicara akan menemui Bah Djan juragan tembakau

di Kota Parakan.

\section{e. Pikiran Positif}

Pikiran positif suatu sikap yang yang melibatkan pikiran, kata-kata dan ada gambar-gambaran yang memunculkan rasa sukacita, kebahagiaan dalam setiap situasi dan perilaku (Andrea, 2011). Kutipan yang ditunjukkan dalam novel Genduk berbunyi :

"Aku pesan sama sampeyan, Yu, hati-hati untuk saat ini. Apalagi kalian cuma berdua. Ganjal setiap pintu dan jendela rapat-rapat setiap malam. Rumah kalian ini agak jauh dari tetangga. Kalau sampai ada..." Lik Ngadun terdiam. “...ah sudalah. Kita berpikir positif dan selalu meminta pertolongan sama Sang Tukang Ngecat Lombok saja," katanya.

(Mardjuki, 2016: 181) Berdasarkan kutipan di atas menunjukkan pikiran positif, karena Lik Ngadun tetap menyuruh Yung dan Genduk 
untuk berpikir positif dan semua dipasrahkan kepada Tuhan.

\section{f. Rasa Syukur}

Rasa syukur adalah rasa yang mengingat suatu kenikmatan dan menampakannya. Rasa syukur adalah sikap yang muncul dari hati yang merasakan suatu keikhlasan yang telah menyadari dengan adanya nikmat dari Tuhan (Kokoh Dwiko Listanto, 2015). Kutipan yang ditunjukkan dalam novel Genduk berbunyi :

Aku melihat Kaji Bawon sambil tersenyum. Aku bersyukur, ada Kaji Bawon yang bisa menyatukan serpihan-serpihan sejarah hidupku. Tetapi kemudian sekelebat bayangan muncul. Aku menunduk. Kurapatkan bibir. Benakku bercamuk ketika tentang Yung melintas. Udara kembali terasa pengap.

(Mardjuki, 2016: 32) Berdasarkan kutipan di atas menunjukkan rasa syukur, karena Genduk merasa bersyukur akan ada Kaji Bawon sejarah hidupnya Genduk menjadi jelas.

\section{HASILENELITIAN PEMBAHASAAN}

DAN

Berdasarkan hasil penelitian mengenai aspek kesejahteraan dan aspek kedamaian dalam novel Genduk ternyata tidak sepenuhnya terdapat jenis-jenisnya. Dalam aspek kesejahteraan ada enam yang terkandung dalam novel tersebut, yaitu pendidikan, pengelolaan gender, kerja keras, gotong royongg, pendidikan, pelestarian budaya dan pedulli lingkungan. Dalam kerja keras terdapat pada tokoh Genduk yang berusaha dalam pengisian air gentong dan mengerjakan tugas rumah seperti menyapu dan menyiapkan makanan. Ada juga para petani yang berkerja keras untuk berladang dari masa penanaman hingga panen tiba. Tokoh Lik Ngadun dan Genduk juga berusaha untuk pergi menemui Bah Djan agar panennya mendapatkan harga tinggi.

Dalam pendidikan berdasaran hasil penelitian bahwa anak-anak desa melakukan pembelajaran di Balai desa. Dalam hasil penelitian juga, menceritakan bahwa Pak'e mengajar ngaji dan masa muda dihabiskan untuk menyantri di Pondok Pesantren. Pada gotong royong dalam hasil penelitian menjelaskan bahwa warga desa sangat berantusias dalam membantu berbagai kegiatan, seperti membangun langgar. Tokoh Genduk juga selalu membantu Yung pada saat berladang untuk menggulung daun-daun tembakau.

Pada pengelolaan gender dalam hasil penelitian sangat jelas bahwa Yung pada saat masih muda hingga bersuami tetap melakukan berladang dari memacul, mencabuti rumput. Tokoh Pak'e jarang sekali membantu Yung. Dalam hasil penelitian pelestarian budaya sangat dilestarikan seperti acara selamatan desa, acara Among Tebal pada saat awal penanaman bibit tembakau. Ada juga acara pemotongan rambut gombak milik Darmaji anak Kang Kisut dan disambut dengan meriah serta diselenggaran acara Jatilan. Pada peduli lingkungan dalam hasil penelitian ini menjelaskan bahwa para petani sangat mengelola ladangnya dengan baik.

Berdasarkan hasil penelitian aspek kedamaian pada novel terdapat lima jenis, antara lain 
kesopansantunan, kejujuran, kesetikawanan sosial, penyelesaian konflik, pikiran positif dan rasa syukur. Pada kesopansantunan terdapat pada tokoh Genduk yang bersikap sangat sopan terhadap orangorang di desa. Dalam hasil penelitian mengenai kejujuran dilakukan oleh tokoh Genduk. Banyak jujur terhadap diri sendiri atau perasaan yang tidak sesuai apa yang dilihat.

Pada kesetikawanan sosial dalam hasil penelitian ini memiliki jiwa pengorbanan yang besar pada tokoh Genduk karena telah menyelamat anak kecil yang hampir tertabrak oleh truk. Dalam hasil penelitian mengenai penyelesaian masalah terdapat pada tokoh Genduk yang berhasil membebas kemiskinan atas ulah Kaduk. Pada pikiran positif dalam hasil penelitian juga bercondong pada tokoh Genduk bahwa bapaknya masih hidup di Kota Parakan. Dalam hasil penelitian rasa syukur lebih bercondong pada tokoh Genduk bersyukur atas nikmat yang diberikan dapat makan setiap hari dan atas adanya Kaji Bawon hidup menjadi jelas akan asal-usulnya.

\section{SIMPULAN DAN SARAN}

Dalam hasil penelitian dapat ditarik sebuah simpulan dalam cerita novel Genduk memberikan sebuah karakter untuk menjadi hidup yang sejahtera dan damai. Dikatakan sejahtera dan damai karena kebudayaan yang dilestarika dalam desa Ringinsari, dekat Gunung Sindoro masih dilakukan dengan baik. Peduli lingkungan yang terdapat dalam novel mengenai cara penanaman bibit tembakau sampai proses pemetikan, peranjangan hingga dijual di pasaran. Kehidupan manusia yang digambarkan sangat lah bagus dalam interaksi antara individu maupun kelompok. Kesetikawanan sosial dan gotong royong sangat kompak dilakukan. Tokoh-tokoh yang diceritakan juga memiliki karakter yang sopan dan santun. Penjelasan tersebut masuk ke dalam aspek kesejateraan dan kedamaian dari bagian jenis kearifan lokal.

Sesuai dengan penelitian di aatas penliti mengajukan saran, antara lain nillai kearifan lokal yang terkandung dalam novel dijadikan ssebagai acuan dallam membentuk sebuah karaktter. Bagi para peneliti sastra selanjutnya, diharapkan lebih sempurna dan lebih luas untuk karya sastra dalam meneliti menggunakan kearrifan lokal dari berrbagai aspek. Hal tersebut, membuat pembaca satra mengenai keariifan lokal akan menjadi lebih paham. Terakhir, bagi peneliti sastra selanjutnya harus banyak mencari sumber informasi dari berbagai pakar ahli agar menjadi bahan perbandingan dan mendapat informasi lebih lengkap.

\section{DAFTAR PUSTAKA}

Endraswara, Suwardi.2008. Metodologi Penelitian Sastra.Yogyakarta : Med Press.

Erlangga, Faisal.2013. Pengertian, Jenis, Sumber, dan Strategi Penyelesaian Konflik.Diakses pada tanggal 9 Oktober 2020 www.google.co.id.

Fadillah, Siti.2016. Kejujuran (Pengertian Kejujuran, Manfaat Kejujuran, Contoh Perilaku Jujur). Diakses pada tanggal 9 Oktober 2020 http://sitiffadillah.blogspot .co.id. 
Handayani Trisakti dan Sugiarti. 2008. Analisis Gender dan Tranformasi Sosial.

Yogyakarta: Pustaka Belajar

Haryanto. 2012. Pengertian Pendidikan Menurut Para Ahli di akses pada tanggal $21 \quad$ Januari2021 http://belajarpsikologi.com /pengertian-pendidikan

Julvengenz.2012. Definisi Berpikir Positif. Diakses pada tanggal 9 Oktober 2020 www.google.co.id.

Kaelan. 2005. Metode Penelitian Kualitatif Bidang

Filsafat. Yogyakarta: Paradigma.

Kamus Besar Bahasa Indonesia. 2014. Edisi Lux.

Semarang: Widya Karya Kurniawati, Sarah. 2014. "Arti dan Makna Kesetikawanan Sosial". Diakses pada tanggal 9 Oktober 2020 http://saarahku.blogspot.co .id.

Listanto, Kokoh Dwiko. 2015. Pengertian Sikap

Bersyukur dan Manfaatnya. Diakses pada tanggal

9

2020,

Oktober

http://kokohnaxnetig.blogs pot.co.id.

Mardjuki, Sundari. 2016. Genduk. Jakarta: Gramedia

Pustaka Ut

Moleong, Lexy.2008. Metodologi Penelitian Kualitatif.

Bandung: Remaja Rosdakarya.

Muzayani. 2019. Nilai-Nilai Pendidikan Akhlak dalam

Novel Iqra' Karya Reza Nufa. IAIN Pekalongan. Nurgiantoro, Burhan.2013. Teori Pengkajian Fiksi.
Yogyakarta: Gajah Mada University Press

Rahayu, $\quad$ Srikandi. 2015. "Pengertian Kerukunan".

Diakses pada tanggal 9

Oktober 2020 http://seputarpengertian.bl ogspot.co.id.

Sibarani, Robert.2014. Kearifan Lokal Hakikat, Peran, dan Metode Tradisi Lisan. Jakarta: Asosiasi Tradisi Lisan.

Sibarani, Robert.2012. Kearifan Lokal Hakikat, Peran, dan Metode Tradisi Lisan. Jakarta: Asosiasi

Tradisi Lisan.

Staff. 2018. “Arti Makna Pengertian dan Definisi dari kesopansantunan”. Diakses pada tanggal 9 Oktober

2020 www.apaarti.com.

Sugiyono.2008. Metode Penelitian Kuantitatif, Kualitatif dan R\&D. Bandung : Alfabeta.

Wahidi, Fadli Rahman. 2017. Pengertian dan ManfaatPelestarian Menurut Ahli. Diakses pada tanggal 9 Oktober 2020 http://globallavebookx.blogs pot.co.id 